\title{
Studies on the Polymerization of Acrolein Oxime. VIII. Formation of Poly(acrolein oxime)-Copper(II) Complexes and Absorption of Molecular Oxygen by the Complexes
}

\author{
Seizo MASUdA, ${ }^{*}$ Ichiro NAKABAYASHI, ${ }^{*}$ Tadatoshi OTA, ${ }^{*}$ \\ and Kiichi TAKEMOTO** \\ * Department of Applied Chemistry, Faculty of Engineering, \\ Tokushima University, Tokushima 770, Japan. \\ **Department of Petrochemistry, Faculty of Engineering, \\ Osaka University, Suita, Osaka 565, Japan.
}

(Received February 13, 1979)

\begin{abstract}
Acrolein oxime was polymerized under different conditions. Formation constants for poly(acrolein oxime)-copper(II) complexes were determined by applying the modified Bjerrum method. The polymers form stronger complexes than their monomeric analogues. The formation constants for polymer complexes are dependent on the oxime group content in the polymer used. An aqueous solution of polymer complexes can effectively absorb molecular oxygen. The mechanism of the absorption is considered to involve cyclic redox reaction of copper ions: a copper(II) ion is reduced by the coordinated poly(acrolein oxime) to a copper(I) ion and the resultant copper(I) ion is oxidized by oxygen to the copper(II) ion.
\end{abstract}

KEY WORDS Poly(acrolein oxime)-Copper(II) Complex / Complexation

Constants / Oxygen Absorption / Oxidation-Reduction /

Acrolein oxime (AOM) can be anionically polymerized on heating to give a polymer whose molecular weight ranges from 2000 to 3000 . Poly(acrolein oxime) (PAOM) contains 1,2-addition, 1,4-addition, and two types of hydrogen transfer structures. Half of the overall structures is known to be the 1,2addition-type of structural unit with a pendant oxime group ${ }^{1}$. In addition, AOM also undergoes polymerization in the presence of anionic and cationic catalysts. PAOM produced by butyllithium catalyst, compared with that obtained thermally, generally has a lower molecular weight ( $c a .1000$ ) and forms a similar proportion of the structural units. $^{2}$ On the other hand, PAOM with a low molecular weight (a few hundreds) and with a high content of oxime group could be obtained by hydrochloric acid catalyst. ${ }^{3}$ PAOMs obtained under different conditions of polymerization differ from one another in physical properties such as solubility.

The complexation constant of PAOM with metal ions also seems to depend on the structure of the ligand. The complexation constants have been determined by Mutō et al. ${ }^{4}$ based on the assumption that PAOM contains only structural units having the pendant oxime group. Since PAOM contains, in practice, a variety of structural units, the formation constant of the complex is measured using modified Bjerrum method ${ }^{5}$ and considering the oxime group content.

Mixing of aqueous solutions of PAOM and copper(II) nitrate produces a complex which is capable of absorbing molecular oxygen. The absorption behavior is considered to differ from that of the solid complex. The present paper deals with the absorption of molecular oxgen by an aqueous solution of PAOM-copper(II) complexes.

\section{EXPERIMENTAL}

\section{Materials}

AOM and propionaldoxime(POM) were prepared by oximation of acrolein and propionaldehyde with hydroxylamine hydrochloride, respectively. $^{6}$ Polymers were prepared as follows: (1) A polymer (PAOM-I) was produced by thermal bulk polymerization at $60^{\circ} \mathrm{C}^{-1}$ (2) a polymer (PAOM-II) was 
produced by bulk polymerization at $30^{\circ} \mathrm{C}$ in the presence of butyllithium; ${ }^{2}$ and (3) a polymer (PAOM-III) was obtained by hydrochloric acidcatalyzed polymerization at $0^{\circ} \mathrm{C}$ using dichloroethane as a solvent. ${ }^{3}$

\section{Characterization}

The number of carbon-carbon double bonds was calculated by determining the iodine value. ${ }^{7}$ The oxime group in PAOM was determined by the Van Slyke method. ${ }^{8}$ The molecular weight of PAOM was determined in a dimethylformamide solution at $70^{\circ} \mathrm{C}$ using a vapor-pressure osmometer (Hitachi PerkinElmer, model 115).

\section{pH Titrations}

Since PAOM is insoluble in water and soluble in acidic and basic solutions, back-tiration was performed with a Hitachi-Horiba $\mathrm{H}-5 \mathrm{pH}$ meter at $20^{\circ} \mathrm{C}$ for constant ion strength: to an alkali solution of PAOM was added aqueous copper(II) nitrate and the solution was then titrated with nitric acid. Precipitation occurred at neutral $\mathrm{pH}$ value, and the precipitate dissolved again in the acidic region. When the precipitate was present, a constant $\mathrm{pH}$ value was attained only after a long time. All readings were taken after the $\mathrm{pH}$ had attained equilibrium; the $\mathrm{pH}$ values have been found to be identical whether the readings were made with the electrodes immersed only in the supernatant solution or in the gel phase. ${ }^{9}$

\section{Manometric Measurements}

The volumes of molecular oxygen absorbed by the aqueous solution of the complex were measured manometrically using a conventional Warburg apparatus.

\section{Potential Measurements}

The potential was referred to the saturated calomel electrode (SCE) using platinum wire as the cathode; the electrolyte was a solution of PAOM, copper(II) nitrate, and potassium nitrate, which was added to keep the ion strength constant.

\section{RESULTS AND DISCUSSION}

\section{Complexation Constants of $\mathrm{Cu}(\mathrm{II})$ with $\mathrm{PAOM}$}

AOM was polymerized under different conditions. Table I shows the characterizations of the PAOM
Table I. Characteristics of PAOM

\begin{tabular}{lccc}
\hline PAOM & $\begin{array}{c}\text { \% of } \mathrm{C}=\mathrm{C} \\
\text { bond }^{\mathrm{a}}\end{array}$ & $\begin{array}{c}\text { \% of oxime } \\
\text { group }^{\mathrm{b}}\end{array}$ & $\begin{array}{c}\text { Molecular } \\
\text { weight }\end{array}$ \\
\hline PAOM-I & 42.0 & 46.0 & 2100 \\
PAOM-II & 50.7 & 42.8 & 820 \\
PAOM-III & 14.6 & 73.8 & 556 \\
\hline
\end{tabular}

a $\%$ of structural units having one carbon-carbon double bond per unit.

b $\%$ of structural units having one pendant oxime group per unit.

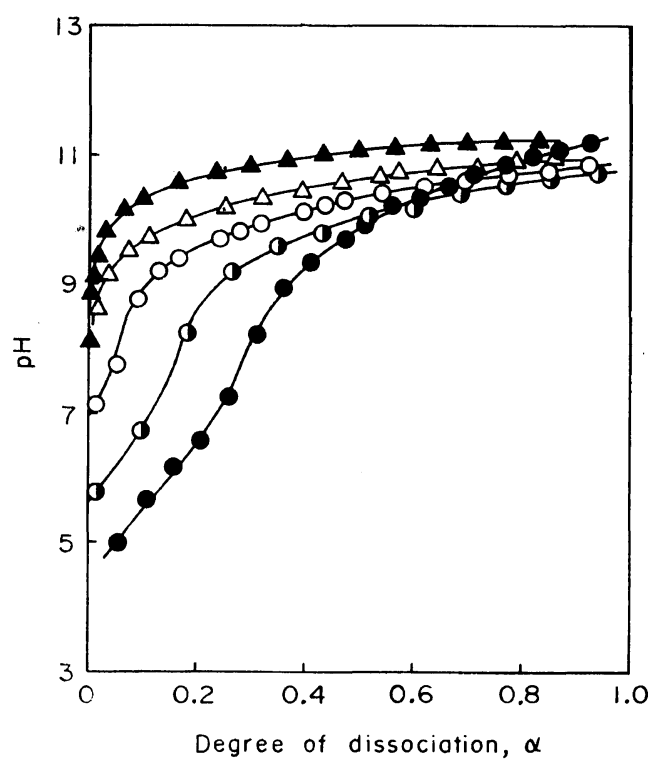

Figure 1. $\mathrm{pH}$ titration of oximes: $\mathrm{O}$, [PAOM$\mathrm{I}]=1.04 \times 10^{-2} \mathrm{~mol} \mathrm{dm}^{-3} ; \mathrm{C},[\mathrm{PAOM}-\mathrm{II}]=1.00 \times 10^{-2}$ mol dm ${ }^{-3} ; 0$, [PAOM-III] $=1.01 \times 10^{-2} \mathrm{~mol} \mathrm{dm}^{-3} ; \triangle$ : $[\mathrm{AOM}]=1.02 \times 10^{-2} \mathrm{~mol} \mathrm{dm}^{-3} ; \mathbf{\Delta},[\mathrm{POM}]=1.09 \times 10^{-2}$ mol dm ${ }^{-3} ; \mu=0.1\left(\mathrm{KNO}_{3}\right)$; temp, $20^{\circ} \mathrm{C}$.

obtained. Figures 1 and 2 show the titration curves for three kinds of PAOM, AOM, and POM as a monomeric analogue, both in the presence and absence of copper(II) nitrate. The titration curve for PAOM-I is found to be analogous to that for the monomer, while PAOM-III gives an S-shaped curve. One possible explanation for these observations is that, the higher the oxime group content in PAOM is, the more favorable and stronger the nearest neighbor interaction among the closely situated oxime group becomes: 
Oxygen Absorption by PAOM-Cu(II) Complexes<smiles>CC(C)/C=N/O</smiles><smiles>CCC(C)C=NO</smiles>

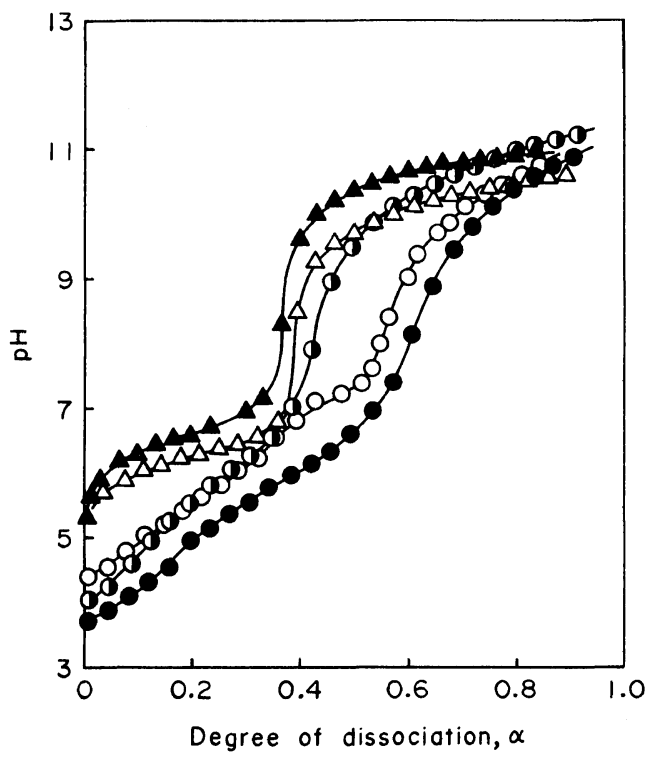

Figure 2. $\mathrm{pH}$ titration of oximes in the presence of copper(II) nitrate: $\left[\mathrm{Cu}\left(\mathrm{NO}_{3}\right)_{2}\right]=1.69 \times 10^{-3} \mathrm{~mol} \mathrm{dm}^{-3}$; $\mathrm{O},[\mathrm{PAOM}-\mathrm{I}]=7.44 \times 10^{-3} \mathrm{~mol} \mathrm{dm}^{-3}, \mathrm{O},[\mathrm{PAOM}-\mathrm{II}]=$ $7.15 \times 10^{-3} \mathrm{~mol} \mathrm{dm}^{-3}, \quad$, $[\mathrm{PAOM}-\mathrm{III}]=7.18 \times 10^{-3}$ $\mathrm{mol} \mathrm{dm}{ }^{-3}, \triangle,[\mathrm{AOM}]=7.27 \times 10^{-3} \mathrm{~mol} \mathrm{dm}^{-3}$, $[\mathrm{POM}]=7.82 \times 10^{-3} \mathrm{~mol} \mathrm{dm}{ }^{-3} ; \mu=0.1\left(\mathrm{KNO}_{3}\right)$; temp, $20^{\circ} \mathrm{C}$.

In the titration curves of PAOM in the presence of $\mathrm{Cu}$ (II) ions, a buffer region can be observed, which suggests that PAOM-Cu(II) complexes are formed.

The Henderson-Hasselbalch plots are given in Figures 3. Although the plots of $\mathrm{pH} v s \cdot \log [(1-\alpha) / \alpha]$, as expected from Figure 1, are linear over a wide range of the degree of dissociation for PAOM-I, AOM, and POM, remarkable deviations from straight lines are observed for PAOM-II and PAOM-III. A similar behavior has been observed in the case of poly(vinylamine hydrochloride). ${ }^{10}$ Kimura et al. explained this behavior on the basis of nearest neighbor interactions among closely situated amino groups, and proposed a modified
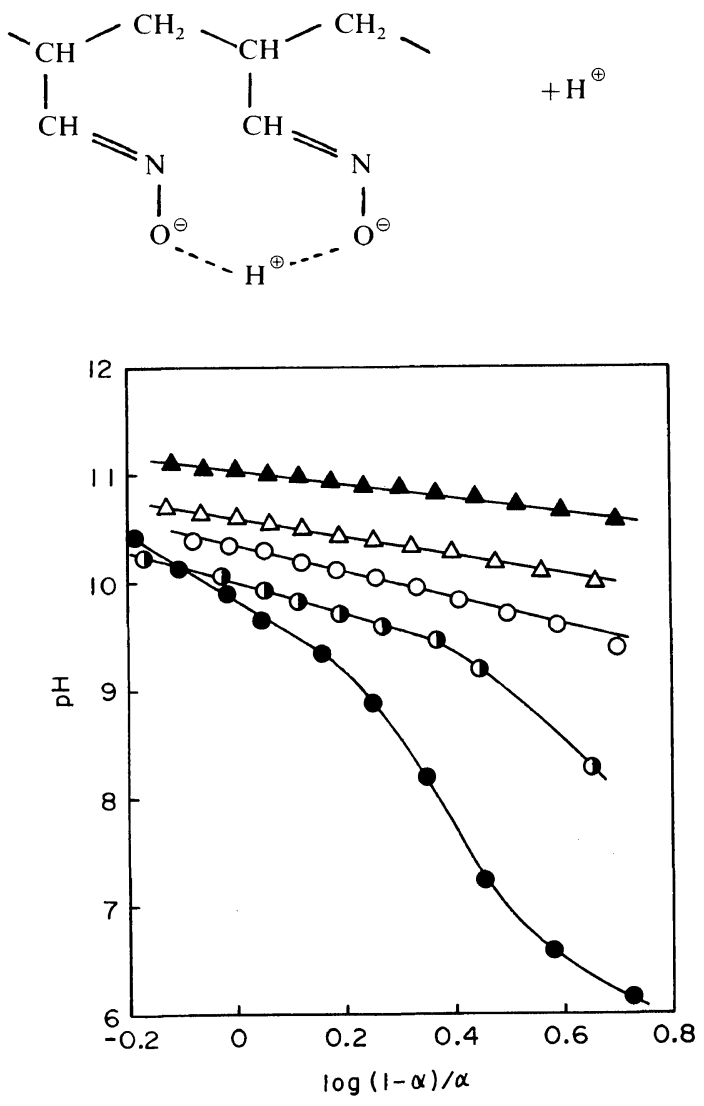

Figure 3. Henderson-Hasselbalch plots of oximes: $\bigcirc$, PAOM-I: 1 , PAOM-II; $\bigcirc$, PAOM-III; $\triangle$, AOM; $\boldsymbol{\Delta}$, POM; $\mu=0.1\left(\mathrm{KNO}_{3}\right)$; temp, $20^{\circ} \mathrm{C}$.

Henderson-Hasselbalch equation. Unfortunately, since there were no modifications of the Henderson-Hasselbalch equation which were applicable to PAOM, the apparent ionization constant $\mathrm{p} K_{\mathrm{a}}$ and the constant $n$ had to be estimated from the linear portion of the plots. The values obtained are summarized in Table II.

Mutō et al. ${ }^{4}$ have obtained $\mathrm{p} K_{\mathrm{a}}=11.6$ and $n=2.36$ for PAOM produced by thermal polymerization, based on the assumption that the polymer consists only of structural units having a pendant oxime group. The values obtained in the present work are different from their results. However, if only 1,2addition is assumed to take place in our case, the agreement is within the experimental error. The valuse of $\mathrm{p} K_{\mathrm{a}}$ and $n$ for PAOM-I are close to those 
Table II. $\mathrm{p} K_{\mathrm{a}}$ and $n$ values for Henderson-Hasselbalch equation

\begin{tabular}{lrl}
\hline \multicolumn{1}{c}{ Oxime } & $\mathrm{p} K_{\mathrm{a}}$ & $n$ \\
\hline PAOM-I & 10.35 & 1.2 \\
PAOM-II & 10.00 & 1.2 \\
PAOM-III & 9.82 & 3.0 \\
AOM & 10.61 & 0.83 \\
POM & 11.07 & 0.71 \\
\hline
\end{tabular}

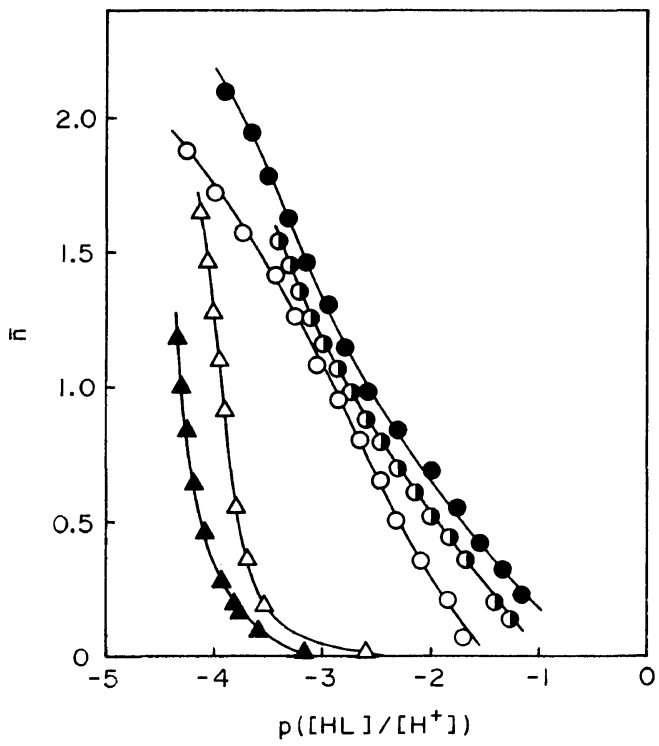

Figure 4. Modified Bjerrum plots for oxime-copper(II) system. The oxime symbols are $\bigcirc$, PAOM-I, O, PAOMII, PAOM-III, $\triangle$, AOM, and $\triangle$, POM. Temp, $20^{\circ} \mathrm{C}$.

for AOM; this may be because the oxime group content is actually up to $50 \%$, that is, a neighboring oxime group would be rare and thus the nearest neighbor interaction would be very weak.

Figure $\dot{4}$ shows plots of $\bar{n} v s$. $p\left([\mathrm{HA}] /\left[\mathrm{H}^{+}\right]\right)$for $0.01 \mathrm{~mol} \mathrm{dm}^{-3}$ oximes and $0.005 \mathrm{~mol} \mathrm{dm}^{-3}$ $\mathrm{Cu}\left(\mathrm{NO}_{3}\right)_{2}$ in the presence of $0.1 \mathrm{~mol} \mathrm{dm}{ }^{-3} \mathrm{KNO}_{3}$. Complexation constants are estimated according to the treatment of Gregor et al. ${ }^{5}$ The values obtaind are summarized in Table III, in which data of Mutō et al. are also listed for comparison. Symbols shown in the table corresponding to the following reactions

$$
\begin{array}{ll}
\mathrm{HL} \rightleftarrows \mathrm{H}^{+}+\mathrm{L}^{+} & K_{\mathrm{a}} \\
\mathrm{HL}+\mathrm{Cu}^{2+} \rightleftarrows \mathrm{CuL}^{+}+\mathrm{H}^{+} & k_{1} \\
\mathrm{HL}+\mathrm{CuL}^{+} \rightleftarrows \mathrm{CuL}_{2}+\mathrm{H}^{+} & k_{2} \\
\mathrm{Cu}^{2+}+2 \mathrm{~L}^{-} \rightleftarrows \mathrm{CuL}_{2} & K^{\prime} \\
& K=k_{1} \times k_{2} \\
& \log K^{\prime}=\log K+2 \mathrm{p} K_{\mathrm{a}}
\end{array}
$$

where $\mathrm{HL}$ and $\mathrm{H}^{+}$represent ligand and proton, respectively. Two metal salts, $\mathrm{Cu}\left(\mathrm{No}_{3}\right)_{2}$ and $\mathrm{CuSo}_{4}$, were used for $\mathrm{AOM}$ and $\mathrm{POM}$, but complexation constants were independent of the paired anions. The table shows strikingly the enhancement of complexation in the case of polymer over that of the monomers, AOM and POM. In the case of PAOM, it is seen that changes in polymerization conditions has no effect on $k_{2}$ and $K^{\prime}$, but a slight effect on $k_{1}$. Roughly, the order of complexation of the ligands was

$$
\begin{aligned}
& \text { POM }<\text { AOM }<\text { PAOM-I }<\text { PAOM-II } \\
& \quad<\text { PAOM-III }
\end{aligned}
$$

The overall stability constant $K^{\prime}$ for PAOM-I is found to be two to three orders larger than that of Mutō et al. In our calculations, the oxime group

Table III. Complexation constants of copper(II) with oximes

\begin{tabular}{cccccc}
\hline Oxime & Metal salt & $\log k_{1}$ & $\log k_{2}$ & $\log K$ & $\log K^{\prime}$ \\
\hline PAOM-I & $\mathrm{Cu}\left(\mathrm{NO}_{3}\right)_{2}$ & -2.33 & -3.53 & -5.86 & 14.84 \\
PAOM-I & $\prime \prime$ & & & -5.7 & 17.5 \\
PAOM-II & $\prime \prime$ & -1.96 & -3.58 & -5.54 & 14.46 \\
PAOM-III & $\prime \prime$ & -1.66 & -3.53 & -5.19 & 14.45 \\
AOM & $\prime$ & -3.78 & -4.09 & -7.87 & 13.35 \\
AOM & $\mathrm{CuSO}_{4}$ & -3.85 & -4.09 & -7.94 & 13.28 \\
POM & ${\mathrm{Cu}\left(\mathrm{NO}_{3}\right)_{2}}_{\text {POM }}$ & -4.10 & -4.50 & -8.60 & 13.54 \\
\hline
\end{tabular}

${ }^{\text {a }}$ Data of Mutō et al. ${ }^{4}$ 
content in PAOM-I was taken as $46 \%$. If the polymer is assumed to consist only of structural units having the pendant oxime group, the $K^{\prime}$ value in the present work becomes similar to theirs.

In a polymer chelate with bivalent metals, neighboring groups along a chain are generally considered to bind the same metal ion. PAOM contains both chelating and nonchelating units, and the cheleting unit must come closer to increase the capability of complexation. This is supported by the fact that the complexation. constants for PAOM-III are greater than that for PAOM-II.

In spite of a similar content of oxime groups, the complexation constant of PAOM-II was slightly greater than that of PAOM-I. It appears that there is no difference in structures of the two PAOM except for molecular weight. It was, however, recognized that a butyl anion can make an attack upon an oxime group, i.e., the carbon-nitrogen double bond (3,4addition) in the equimolar reaction of AOM and butyllithium, and that the subsequent elimination of lithium hydride results in the formation of ketoxime. ${ }^{11}$ Therefore, there may be a slight difference in the structures of the two PAOM. Though an increase in the molecular weight results in an increased number of neighboring groups for a homopolymer, this would not be the case for a polymer containing various structural unlits. The relationship between molecular weight and complexation constant of ligand is ambiguous in the case of PAOM.

It was confirmed by the continuous variation method that a 2:1 complex was formed between AOM and copper(II) nitrate. In addition, the complex was found by elemental analysis to have the composition of 2 moles of AOM to one mole of $\mathrm{Cu}(\mathrm{II}) .{ }^{12}$ These findings are in agreement with the fact that the average number of ligands, $\bar{n}$, is maximum at about 2 (Figure 4), as will be described below. Though there are no data for analyzing the structure of a polymer complex, the behavior is anticipated to be similar to that of an AOM complex.

\section{Absorption of Molecular Oxygen by Aqueous Solutions of Complexes}

Polyoxime-metal complexes have been shown to be gas adsorbents in the solid state by Kim and Takizawa. ${ }^{13}$ In the course of our study of the properties of PAOM-Cu(II)complexes, it was observed that an aqueous solution of these complexes can also absorb molecular oxygen. A similar obser- vation was made in the case of AOM and POM. ${ }^{12}$ In order to examine the capability of the absorption, three kinds of PAOM were studied. When aqueous solutions of PAOM and copper (II) nitrate are mixed together, the mixture becomes green and no percipitation occurs. Figure 5 shows the time course of oxygen consumption. The volumes depend on the

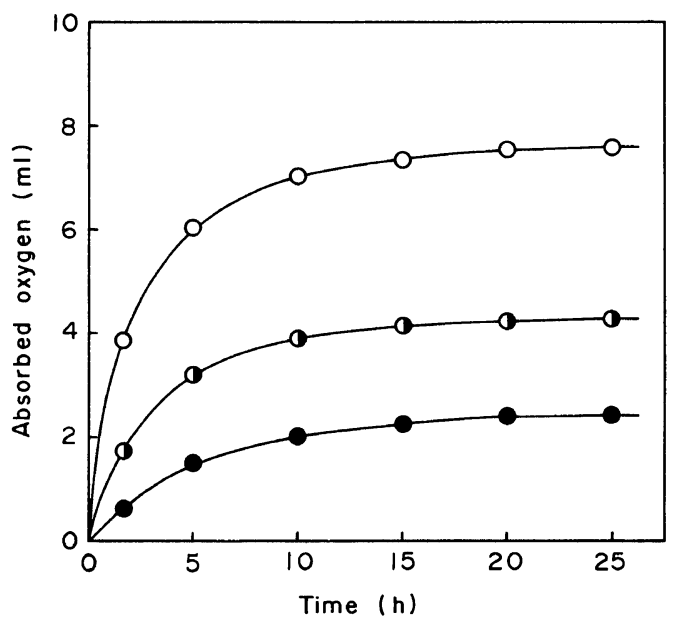

Figure 5. Absorption curves for the complex solutions at room temp: $\left[\mathrm{Cu}^{2+}\right]=0.5 \mathrm{mmol} ; 0,[$ PAOM-I] $=1.0$; ○, $[\mathrm{PAOM}-\mathrm{II}]=1.0 ; \mathrm{O},[\mathrm{PAOM}-\mathrm{III}]=1.0 \mathrm{mmol}$; volume, $8 \mathrm{~cm}^{3}$.

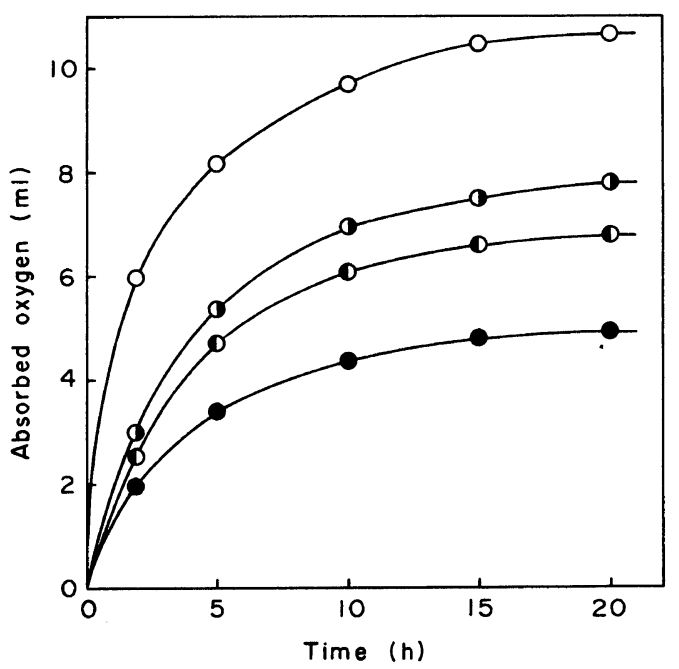

Figure 6. Absorption curves for the solution of PAOMIII-Cu(II) complex at room temp; $\left[\mathrm{Cu}^{2+}\right]=0.534 \mathrm{mmol}$. [PAOM-III]: O, 1.608; O, 1.000; O $0.804 ; \bigcirc 0.530$ mmol; volume, $8 \mathrm{~cm}^{3}$. 


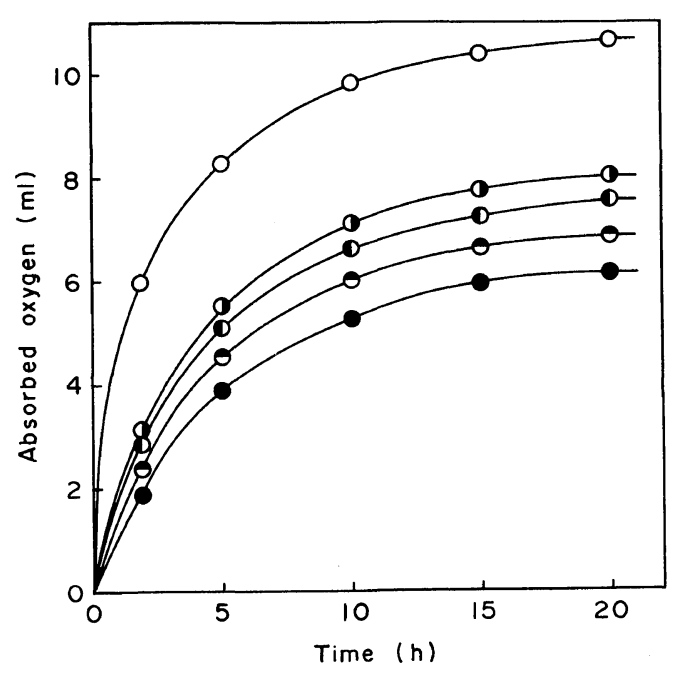

Figure 7. Absorption curves for the solution of PAOMIII-Cu(II) complex at room temp; [PAOM-III] $=1.61$ mmol. $\left[\mathrm{Cu}^{2+}\right]: \bigcirc, 1.07 ; \bigcirc, 0.534 ; \bigcirc, 0.267 ; \boldsymbol{D}, 0.134 ; \bigcirc$, $0.020 ; 0.0134 \mathrm{mmol}$; volume, $8 \mathrm{~cm}^{3}$.

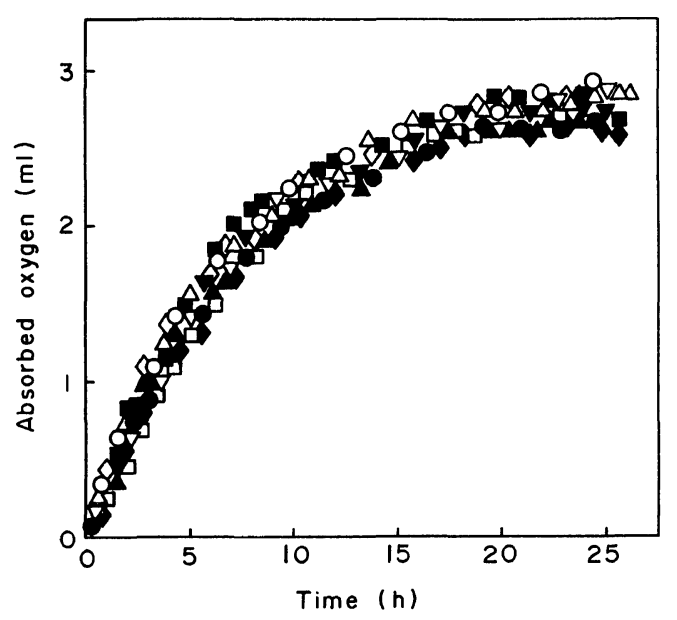

Figure 8. Resorption curves for the complex solutions at room temp: $\mathrm{O}, \mathrm{O},[\mathrm{PAOM}-\mathrm{III}]=1.87,\left[\mathrm{Cu}^{2+}\right]=1.00$; $\square, \mathbf{\square},[\mathrm{PAOM}-\mathrm{III}]=0.94,\left[\mathrm{Cu}^{2+}\right]=1.00 ; \triangle, \boldsymbol{\Delta},[\mathrm{PAOM}-$ $\mathrm{III}]=0.94,\left[\mathrm{Cu}^{2+}\right]=0.5 ; \quad \nabla, \quad \nabla,[\mathrm{PAOM}-\mathrm{III}]=0.47$, $\left[\mathrm{Cu}^{2+}\right]=1.00 ; \diamond, \diamond,[$ PAOM-III $]=0.47,\left[\mathrm{Cu}^{2+}\right]=0.50$ mmol; resorption $(\bigcirc, \square, \triangle, \nabla, \diamond)$ and repeated resorption $(\boldsymbol{\bullet}, \boldsymbol{\Delta}, \boldsymbol{\nabla}, \bullet)$; volume, $8 \mathrm{~cm}^{3}$. oxime group content in PAOM, and the PAOM-III complex, in which such content is a maximum, effectively absorbed oxygen. Because PAOM-II differs from PAOM-I in structure, as described above, in spite of the similar content of oxime groups, there is a difference in absorption capability between their copper complexes. The order of the capability is the same as that of the complexation constant.

Figures 6 and 7 indicate the dependence of the volumes of the absorbed oxgen on copper(II) ion and PAOM-III concentrations. The total volumes increase with time and level off within $20 \mathrm{~h}$. In a definite concentration of PAOM-III (1.61 mmol), 1.07 and $0.54 \mathrm{mmol}$ of copper(II) nitrate gave similar absorption curves, and the total volumes decrease slightly with decreasing concentration of copper(II) nitrate. However, the volume of the absorbed oxgen seems to be substantially independent of the concentration of metal salt present; a solution in which copper(II) nitrate had been reduced to one-eightieth of its original concentration, 1.07 to $0.034 \mathrm{mmol}$, could still absorb as much as $60 \%$ of its original volume. On the other hand, for a definite concentration of copper(II) nitrate, the volumes of oxygen absorbed depend on the concentration of PAOM-III present.

Figure 8 shows reabsorption curves for solutions of PAOM-III-Cu(II) complexes. The complex solutions first leveled off, then were desorbed for $3 \mathrm{~h}$ at room temperature under reduced pressure $[3 \mathrm{mmHg}$ $(0.4 \mathrm{kPa})]$; absorption-desorption was repeated once more under similar conditions. The repeated resolved oxygen volumes are independent of concentration of PAOM-III and $\mathrm{Cu}(\mathrm{II})$ ions and are found to be approximately $2.7 \mathrm{~cm}^{3}$. This amount may be ascribed to the volume of a simple sorption, in other words, the volume of reversible absorption.

The total volumes of absorbed oxygen are summarized in Table IV. The molar ratios of absorbed oxygen to oxime group in PAOM are in the range of 0.26 to 0.34 . Thus four moles of oxime group may react with one mole of molecular oxygen in the presence of copper ions.

From these results, the oxygen absorption may be explained on the basis of the oxidation-reduction of copper ions. When $\mathrm{Cu}(\mathrm{II})$ ions are reduced to $\mathrm{Cu}(\mathrm{II})$ ions, there are two possible paths. 
Oxygen Absorption by PAOM-Cu(II) Complexes

(A)

$\begin{aligned}-\mathrm{CH}_{2}- & \mathrm{CH})_{n} \\ & \mathrm{CH}=\mathrm{N}-\mathrm{OH}\end{aligned}$

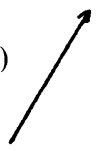<smiles>[C+]CC=NO</smiles>

(B)<smiles></smiles><smiles>CCCC=NO</smiles><smiles>CCCC(C=NO)CC</smiles>

As will be described later, the reaction probably proceeds by path (B). On the other hand, the resultant $\mathrm{Cu}(\mathrm{I})$ ions are easily oxidized by oxygen to $\mathrm{Cu}(\mathrm{I})$ ions. Consequently, the cyclic redox reaction of copper ion is repeated until the oxime group is consumed. In other words, the total volumes of absorbed oxygen depend on the concentration of PAOM present.

$$
\mathrm{Cu}(\mathrm{II}) \stackrel{-\mathrm{CH}=\mathrm{N}-\mathrm{OH}}{\underset{\mathrm{O}_{2}}{\rightleftarrows}} \mathrm{Cu}(\mathrm{I})
$$

Potentiometric experiments were performed in order to prove the assumption mentioned above. The potential for the solution of copper(II) nitrate was found to be $0.376 \mathrm{~V}$. When a definite amount of PAOM is added to the solution in nitrogen atmosphere, as shown in Figure 9, it tends to become lower with time, and rises again when the atmosphere is replaced with oxgen. Durig the period of potential increase, the solution can absorp oxygen, and when the oxygen absorption ceases the potential also levels off. This fact provides strong evidence in con-

Table IV. Absorption of molecular oxygen by PAOM-III-Cu(II) complexes in aqueous solution at room temperature

\begin{tabular}{|c|c|c|c|c|c|}
\hline 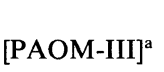 & \multirow{2}{*}{$\begin{array}{l}\text { mmole of oxime } \\
\text { group [A] }\end{array}$} & \multirow{2}{*}{$\frac{\left[\mathrm{Cu}^{2+}\right]}{\mathrm{mmol}}$} & \multirow{2}{*}{$\begin{array}{c}\begin{array}{c}\text { Total amount of } \\
\text { absorbed oxygen }[\mathrm{B}]\end{array} \\
\mathrm{cm}^{3}(\mathrm{mmol})\end{array}$} & Resorbed oxygen [C] & \multirow{2}{*}{$\frac{[\mathrm{B}]-[\mathrm{C}]}{[\mathrm{A}]}$} \\
\hline $\mathrm{mmol}$ & & & & $\mathrm{cm}^{3}(\mathrm{mmol})$ & \\
\hline $1.04^{\mathrm{b}}$ & $4.78 \times 10^{-1}$ & $9.94 \times 10^{-2}$ & $2.5(0.10)$ & & \\
\hline $1.00^{\mathrm{c}}$ & $4.48 \times 10^{-1}$ & $9.94 \times 10^{-2}$ & $4.3(0.18)$ & & \\
\hline 1.01 & $7.45 \times 10^{-1}$ & $9.94 \times 10^{-2}$ & $7.6(0.31)$ & & \\
\hline 1.87 & 1.38 & 1.00 & $12.6(0.52)$ & $2.7 \pm 0.5(0.11 \pm 0.02)$ & $0.29 \pm 0.02$ \\
\hline $9.40 \times 10^{-1}$ & $6.94 \times 10^{-1}$ & 1.00 & $7.7(0.31)$ & $2.7 \pm 0.5(0.11 \pm 0.02)$ & $0.28 \pm 0.03$ \\
\hline $4.70 \times 10^{-1}$ & $3.47 \times 10^{-1}$ & 1.00 & $4.7(0.20)$ & $2.7 \pm 0.3(0.11 \pm 0.01)$ & $0.26 \pm 0.03$ \\
\hline $4.70 \times 10^{-1}$ & $3.47 \times 10^{-1}$ & $5.00 \times 10^{-1}$ & $5.5(0.23)$ & $2.7 \pm 0.3(0.11 \pm 0.01)$ & $0.34 \pm 0.03$ \\
\hline 1.61 & 1.19 & 1.07 & $10.6(0.43)$ & & \\
\hline 1.61 & 1.19 & $5.34 \times 10^{-1}$ & $10.6(0.43)$ & & \\
\hline 1.61 & 1.19 & $2.67 \times 10^{-1}$ & $8.0(0.33)$ & & \\
\hline 1.61 & 1.19 & $1.34 \times 10^{-1}$ & $7.5(0.31)$ & & \\
\hline 1.61 & 1.19 & $1.34 \times 10^{-2}$ & $6.2(0.25)$ & & \\
\hline 1.00 & $7.38 \times 10^{-1}$ & $5.34 \times 10^{-1}$ & $7.1(0.29)$ & $(0.09)$ & 0.27 \\
\hline $8.00 \times 10^{-1}$ & $5.90 \times 10^{-1}$ & $5.34 \times 10^{-1}$ & $6.7(0.27)$ & & \\
\hline
\end{tabular}

a Oxime group content of PAOM-III is $73.8 \%$.

b PAOM-I was used. Its oxime content is $46.0 \%$.

c PAOM-II was used. Its oxime content is $44.8 \%$. 


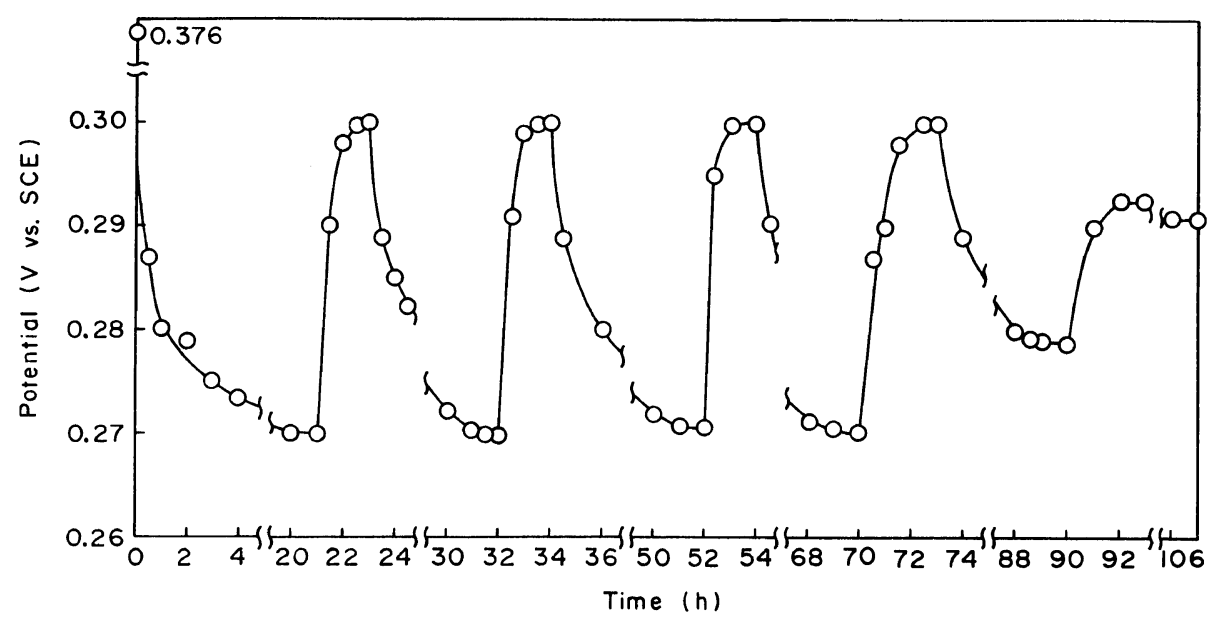

Figure 9. Potential change for PAOM-III-Cu(II) complex system at room temp; [PAOM-III] $=5 \mathrm{mmol}$; $\left[\mathrm{Cu}^{2+}\right]=2.5 \mathrm{mmol} ; \mu=0.5\left(\mathrm{KNO}_{3}\right)$.

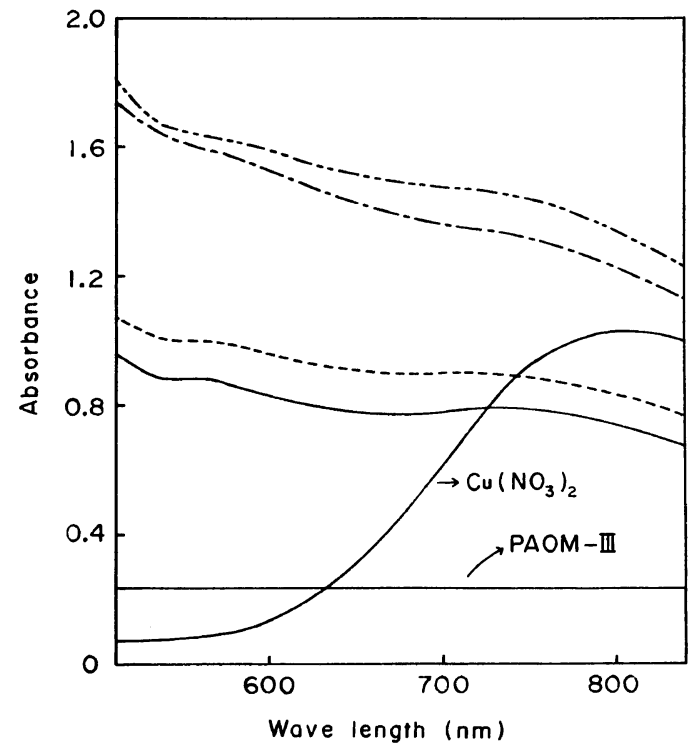

Figure 10. Change in absorption for PAOM-III-Cu(II) system in the atmosphere of nitrogen: after $0.3(-\cdots)$, $2.5(--), 6(----)$, and $15(-) \mathrm{h} ;[$ PAOM-III $]=0.8$ $\mathrm{mol} \mathrm{dm}{ }^{-3} ;\left[\mathrm{Cu}\left(\mathrm{NO}_{3}\right)_{2}\right]=0.4 \mathrm{~mol} \mathrm{dm}^{-3}$.

firmation of the oxidation-reduction of copper ions.

Copper(II) nitrate and copper(II) complexes show the absorption bands at $c a .750$ and $c a .570 \mathrm{~nm}$, respectively. In the atmosphere of nitrogen (Figure 10), the absorbance was found to decrease with time, but the shape of the curves remained un-

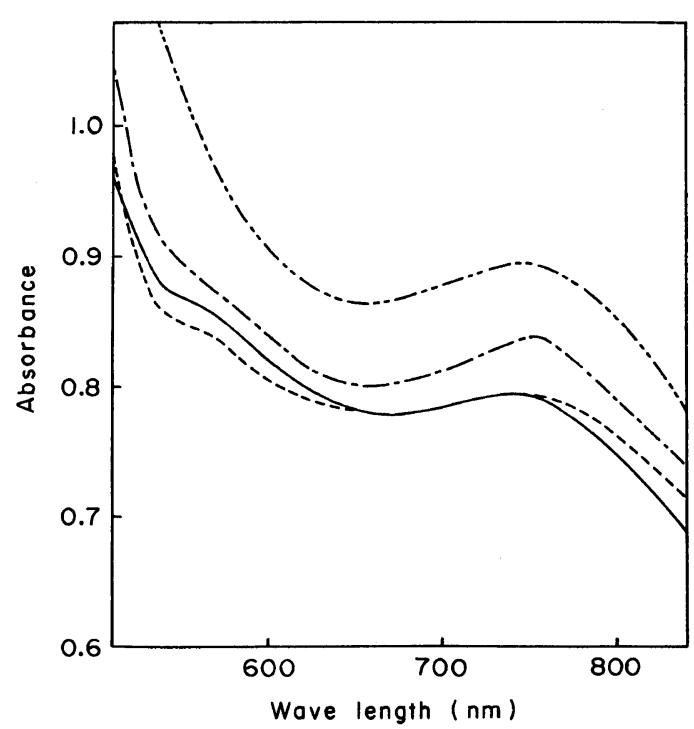

Figure 11. Change in absorption for PAOM-III-Cu(II) system in the atomosphere of oxygen: after 0 (-), 3 $(--), 8(--)$, and $24(-\cdots) \mathrm{h}$; [PAOM-III] $=0.8$ $\mathrm{mol} \mathrm{dm}-3 ;\left[\mathrm{Cu}\left(\mathrm{NO}_{3}\right)_{2}\right]=0.4 \mathrm{~mol} \mathrm{dm}^{-3}$.

changed.When the atmosphere was replaced with oxygen (Figure 11), the intensity at $750 \mathrm{~nm}$ became stronger with time, but the band at $570 \mathrm{~nm}$, identified as an $d-d$ transition, overlaps with a lower wavelength band, and the intensity did not change remarkably. These findings also support the occur- 


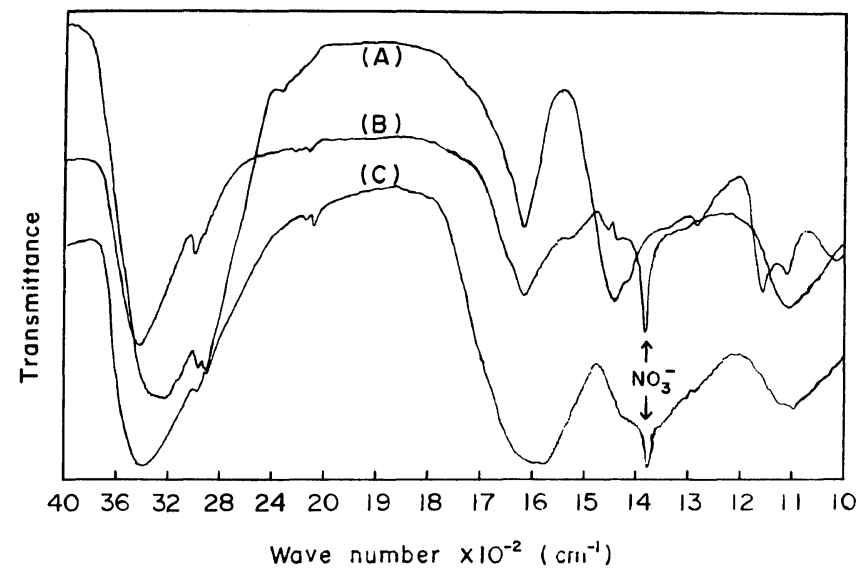

Figure 12. IR spectra of PAOM-III and its copper(II) complex: A, PAOM-III; B, PAOM-III-Cu(II) complex prepared in the presence of nitrogen; C, PAOM-III-Cu(II) complex absorbed oxygen.

rence of a redox reaction of copper ions.

Figure 12 shows IR spectra of PAOM-III and its copper(II) complexes (oxime $/ \mathrm{Cu}(\mathrm{II})=2 / 1$ by mole). The complex solution was evaporated in nitrogen atmosphere and the IR spectrum of the precipitate was quickly measured in a $\mathrm{KBr}$ disc. The shift of the $\mathrm{O}-\mathrm{H}$ stretching to a considerably lower frequency $\left(3200 \mathrm{~cm}^{-1}\right)$, shown in spectrum (A), indicates the formation of hydrogen bonds of two types, $\mathrm{O}-\mathrm{H}---$ $\mathrm{N}$ and $\mathrm{O}-\mathrm{H}---\mathrm{O} ;{ }^{14}$ the lower frequency value $\left(1620 \mathrm{~cm}^{-1}\right)$ of the $\mathrm{C}=\mathrm{N}$ stretching suggests participation of nitrogen atoms in the hydrogen bonding. When $\mathrm{Cu}(\mathrm{II})$ ions are added to PAOM-III solution in the presence of nitrogen, the hydrogen bond of the $\mathrm{O}-\mathrm{H}---\mathrm{N}$ type is broken and the nitrogen atom in the oxime group coordinates again to the $\mathrm{Cu}(\mathrm{II})$ ions. Consequently, the band at $3220 \mathrm{~cm}^{-1}$ is shifted to $3440 \mathrm{~cm}^{-1}$ and the absorption due to the $\mathrm{C}=\mathrm{N}$ stretching bocome broad but does not shift (Figure 12(B)). When the complex thoroughly absorbs oxygen, the absorptions due to the $\mathrm{O}-\mathrm{H}$ stretching and the $\mathrm{C}=\mathrm{N}$ streching become slightly broad with no shift and broad with a shift to $1570 \mathrm{~cm}^{-1}$, respectively (Figure $12(\mathrm{C})$ ). This finding suggests that electron transfer from the nitrogen atoms in oxime groups helps to derive $\mathrm{Cu}(\mathrm{II})$ ions toward $\mathrm{Cu}(\mathrm{I})$ ions. The absorption due to the $\mathrm{CH}_{2}$ deformation, which appears at $1450 \mathrm{~cm}^{-1}$, diminishes in the IR spectra of the complex because of the disorder of structure. In addition, the absorption peak assigned to $\mathrm{NO}_{3}{ }^{-}$ stretching vibration appears at $1380 \mathrm{~cm}^{-1}$.

\section{REFERENCES}

1. S. Masuda, and T. Ota, Polym. J., 9, 459 (1977).

2. S. Masuda, M. Tanaka, and T. Ota, Polym. J., 10, 387 (1978).

3. S. Masuda and T. Ota, Polym. J., 10, 397 (1978).

4. N. Mutō, T. Komatsu, and T. Nakagawa, Nippon Kagaku Zasshi, 92, 43 (1971).

5. H. P. Grogor, L. B. Luttinger, and E. M. Loebl, J. Phys. Chem., 59, 34 (1955).

6. S. Masuda, H. Kihara and T. Ota, Nippon Kagaku Kaishi, 608 (1974).

7. I. P. Losev and O. Ya Fedotova, "Praktikum po Khimii Vysokopolymernykh Soedinenii," Gosudarstvennoe Nauchno-Tekhnicheskoe Izdatelistvo Khimicheskoi Literatur, Japanese translation, Gihōdō, Tōkyo, 1965, p 67.

8. D. D. Van Slyke, Ber., 43, 3170 (1910).

9. H. P. Grogor, J. Phys. Chem., 59, 366, 559, and 990 (1955).

10. K. Kimura, Y. Inaki, and K. Takemoto, Makromol. Chem., 175, 83 (1974).

11. T. Ota, M. Tanaka, and S. Masuda, unpublished data.

12. S. Chikutei, I. Nakabayashi, S. Masuda, and T. Ota, umpublished data.

13. S. J. Kim and T. Takizawa, Makromol. Chem., 175, 125 (1974); 176, 891, 1217 (1975).

14. S. Califano and W. Luttke, Z. Phys. Chem., 5, 240 (1955). 